\title{
BANISHING THE BOGEY OF INCOMMENSURABILITY
}

\section{LARRY ALEXANDER $\dagger$}

I have two major worries whenever I am asked to comment on others' articles. The first is that I will know nothing about the subject, which, given the large number of subjects I know nothing about, is highly likely. The second is that I will agree down the line with the articles on which I am to comment, the probability of which increases with the eminence of the authors, and which becomes almost a certainty if my first worry is borne out.

That is my predicament here. I really have not been a close follower of the literature on incommensurability, having just gotten snatches of it from reading Joseph Raz, ${ }^{1}$ Elizabeth Anderson, ${ }^{2}$ and others. ${ }^{3}$ Ruth Chang ${ }^{4}$ and Lewis Kornhauser ${ }^{5}$ are also very able theorists, both of whom I find quite convincing.

Yet, because Chang and Kornhauser are so good, they actually have saved me from the ignominious fate of having nothing to say. They have caused me to reflect upon certain aspects of the incommensurability debate and to reach some conclusions, though quite tentative ones. What I am interested in are various moral phenomena that might be taken as demonstrating value incommensurability but that I believe do nothing of the sort.

† Warren Distinguished Professor of Law, University of San Diego. I wish to thank the participants in the Symposium on Law and Incommensurability for their excellent comments.

'See Joseph RaZ, THE Morality of Freedom 321-66 (1986).

2 See ElizABETH ANDERSON, VALUE IN ETHICS AND ECONOMICS 55-64 (1993).

${ }^{3}$ See, e.g., Cass R. Sunstein, Incommensurability and Valuation in Law, $92 \mathrm{MrCH}$. L. REv. 779, 795-812 (1994).

${ }^{1}$ Ruth Chang, Comparison and the Justification of Choice, 146 U. PA. L. REV. 1569 (1998).

${ }^{5}$ Lewis A. Kornhauser, No Best Answer?, 146 U. PA. L. REv. 1599 (1998). My comments are somewhat orthogonal to Kornhauser's concerns, which is why I do not comment directly on his fine article. I do, however, agree with his taxonomy of both the private and social-choice aspects of the incommensurability debate and with the implications of those aspects that he describes. 


\section{WHAT INCOMMENSURABILITY IS NOT: A LAUNDRY LIST}

I agree completely with Ruth Chang that to say a choice is justified is to imply the comparability of the thing chosen with those not chosen. $^{6}$ The worry about incommensurability, then, is that if two courses of action are of incommensurable value, the choice between them cannot be justified. ${ }^{7}$ That is surely a problem in the domain of prudence. And it is a huge problem in the domain of moral values, for it raises the specter of moral relativism.

Is there reason to believe that either moral or prudential values are incommensurable, so that many moral or prudential choices cannot be justified? I cannot demonstrate the complete absence of value incommensurability. What I shall attempt to do, however, is point out a number of things that might be taken to reveal value incommensurability but do not, at least not in the way that would undermine justified choice.

\section{A. Hard Choices}

Frequently we are confronted with really difficult choices. Should we pursue a career in law, for which we are moderately talented, and which will allow us to have a conventional family life and considerable comfort? Or should we instead pursue an artistic life, for which we have great talent and love, but which will deprive us of the joys of family and wealth? Should we move our family to a remote wilderness, where we will be free from the pollution, crime, and moral corruption of city life, and where we can share the togetherness brought about by isolation and home schooling? Or should we remain in the city, where our children will have friends their own age and a chance to encounter diverse peoples and values and become cosmopolitan in outlook?

These dilemmas are paradigmatic of many hard choices we or others might face. Do they suggest incommensurable values and thus the incomparability of the chosen paths? I think not.

For one thing, as a matter of phenomenology, the choices seem to be ones that might be unjustified. That is why we anguish over them. If the values truly were incommensurable and the choices in-

${ }^{6}$ See Chang, supra note 4, at 1572.

7 I shall use "incommensurable" throughout as a synonym for "incomparable," although I realize that the terms have different meanings. I believe that the incomparability of values is what usually is being claimed in the incommensurability literature. 
comparable, then why the anguish? If isolation is neither better nor worse than city life, then whichever is chosen is as unjustified as its competitor. One might as well blithely flip a coin. After all, when choices are of equal value-as in picking a number on which to place a bet in roulette-anguish is uncalled for. Anguish seems uncalled for as well in cases in which incommensurability holds.

There is a second reason why these hard choices suggest commensurable rather than incommensurable values. Suppose that in the choice, say, between being a lawyer and being an artist, we alter some of the outcomes. Suppose, for example, that if we become a lawyer, we will be very successful, perhaps with a good chance of being appointed to the Supreme Court. And suppose that if we become an artist, our work will be mediocre at best. The choice to become a lawyer begins to look somewhat better than the choice to become an artist. But if this is so, it suggests that these choices are comparableperhaps the metric of comparability is something like a "deeply satisfying life"-and that what looked like incommensurability was really just epistemic uncertainty within a range. ${ }^{8}$ Once lawyering moves above that range, or being an artist moves below it, we are more confident in the justifiability of the choice of lawyering.

\section{B. Personal Death}

Some values appear incommensurable, I suspect, because the choice of one rather than another would change us in ways that we would view as extinguishing our current selves. At this stage in my life, for example, I cannot envision deserting my family and career in law teaching and running off to Tahiti to paint, even if, quite counterfactually, I possessed the artistic talent of Gauguin. I can imagine another person with (some of) my characteristics doing so, but that someone would not be I.

Does this mean that the values at stake are incommensurable? I do not think so. What it means is that the values are commensurable only for those persons for whom they are accessible. A life like Gauguin's is not accessible to me in any sense that would preserve my personal identity. Although we can change our values over time and maintain continuity of personal identity, we cannot do so radically.

\footnotetext{
${ }^{8}$ Actually, the uncertainty can be either over the structure of the metric by which the life plans are to be compared-how, for example, development of talent properly is traded off against having a family-or over the facts.
} 


\section{Deontological Side-Constraints and Lexical Priorities}

Deontological side-constraints look, from a certain angle, like a case of value incommensurability. After all, if one cannot knowingly take an innocent life to save the lives of thousands of others, or if one cannot lie to a murderer about the whereabouts of his intended victim, then neither lives nor lies can be traded for lives.

This form of value incommensurability, if that is what one wishes to label it, however, is far different from the form that raises problems of justified choice. For deontological side-constraints specify the choice that is justified. They rank particular values-not deliberately taking innocent lives, not lying-as lexically superior to others. On some theories, such as rigorist Kantianism, the lexical superiority is absolute. On others, such as those that contain "moral catastrophe" exceptions, the lexical superiority operates only up to a point.

Theories that postulate a lexical ranking of values, whether within morality, between morality and prudence (with moral values given lexical superiority to prudential ones), or within the domain of prudence, obviously do not give rise to problems of justified choice. For if the theories themselves are justified, then they in turn specify the ranking of the values, which means that the values are commensurable in terms of the theory-specified metric. Deontological theories may not be able to rank outcomes, but that is because they do rank acts.

\section{Counting the Numbers}

In 1977, John Taurek published a highly provocative article entitled, Should the Numbers Count? In it, he argued forcefully, if somewhat counterintuitively, that it was not necessarily true that the loss of several lives is a worse outcome than the loss of fewer but different lives. The argument was not that the fewer lives might be more productive or more virtuous ones, or that their loss might upset more survivors or otherwise more adversely affect the world. The argument, rather, was that even if all the lives were the same along all these dimensions, the loss of more lives could not be regarded as worse than the loss of fewer.

The reason, Taurek argued, is that losses are losses to particular people, and that a loss to a particular person is never offset by a gain (or prevention of a loss) to another particular person. A loss to one is

${ }^{9}$ John Taurek, Should the Numbers Count?, 6 PHIL. \& PUB. AFF. 293 (1977). 
never offset by a gain to another, because there is no particular person for whom these losses and gains can be offset. Taurek's argument was a wrinkle on Robert Nozick's earlier, more general criticism of utilitarianism, namely that utilitarianism improperly conflates the rationality of weighing benefits and burdens across lives with the rationality of weighing benefits and burdens within a life. ${ }^{10}$

Robert Nozick's individualism might entail the incomparability of all gains and losses across individuals. Taurek's argument is not as far-reaching as Nozick's, for Taurek does not deny that a lesser loss to $A$ is to be preferred to a greater loss to $B$. Taurek only denies that the same loss qualitatively is affected by its distribution quantitatively.

Taurek's argument has been resisted by most philosophers, who continue to argue that the loss of more lives is worse than the loss of fewer different ones." Even if Taurek is correct, however, and his critics are wrong, I would think that his argument establishes the equality of similar losses rather than their incommensurability. A loss of $A$ 's life is both morally equal to a loss of $B$ 's life and morally equal as well to a loss of both $B$ 's and $C$ 's lives. The choice between the loss of $A$ 's life and the loss of $B$ 's and $C$ 's lives will have to be governed by some value other than the sanctity of life.

\section{E. Rules and Commitments}

Suppose I decide to do $X$, or commit to doing $X$, or adopt a rule prescribing that $I$ do $X$, because at the time I do so, $X$ appears to be the most justified course of action. When the time comes to perform $X, Y$ looks preferable to $X$. Would the choice of $X$ be rationally justified?

The rationality of adopting rules and making decisions and commitments is based on the paradoxical notion that the most rational course of action to follow-the one that maximizes value-is not the same as making each choice the most value-maximizing one. Without rules, commitments, and decisions, our lives would be impoverished-indeed, unlivable. At any point in time, however, rules, commitments, and decisions stand in the way of our lives being better. There is extensive literature on this point that includes such diverse

\footnotetext{
${ }^{10}$ See Robert NozICK, ANARCHY, STATE, AND UTOPIA 33 (1974).

"One of the best treatments of the "numbers" issue that takes a position opposed to Taurek's can be found in 1 F.M. KAMM, MORALITY, MORTALITY 75-98 (1993).
} 
items as rational precommitments to behave irrationally and the need for serious rules both in law and in personal matters. ${ }^{12}$

The choice between sticking with our rules, commitments, and decisions and optimizing at any given point in time looks arguably like an example of incommensurability. And perhaps it is, though it is not the kind of example to which those who assert value incommensurability point. Indeed, they never mention it. I think it is not at all what they have in mind and is viewed best not as value incommensurability, but as a practical paradox in optimizing among quite commensurable values.

\section{F. Problems of Social Choice}

Many of the phenomena I claimed have been mistaken for value incommensurability cause problems in constructing a social-choice function. Constructing such a function, of course, is bedeviled by Arrow's theorem if we are restricted to ordinal rankings of policies. ${ }^{\text {is }}$ We might overcome that difficulty if we could commensurate and aggregate individuals' policy preferences. But suppose one person values $A$ as lexically superior to $B$-for her, no amount of $B$ could ever make up for the loss of $A$-while another person values $B$ as lexically superior to $A$. How can $A$ 's and $B$ 's values be aggregated in a socialchoice function? Or suppose Taurek is correct, and a loss (or gain) of value $A$ for five people is not worse than or better than a loss (or gain) of value $A$ for one person. Again, how can a social-choice function handle that moral fact?

The problem here is not incommensurability as the term normally is understood. The problem, rather, is the separateness of individuals and what that entails for the multitude of unavoidable choices that affect more than one person.

\section{THE MOTIVATIONS FOR ASSERTING INCOMMENSURABILITY}

I have argued that most cases of what might be thought to be value incommensurability turn out to be something else. Why, then, are theorists so quick to jump to value incommensurability to explain

12 See, e.g., Larry Alexander \& Emily Sherwin, The Deceptive Nature of Rules, 142 U. PA. L. REV. 1191, 1192 (1994) (emphasizing the need for serious rules); see also Thomas C. SChEling, THE StrategY OF CONFLict $37-39$ (1980) (discussing commitments to irrational actions as rational conflict-resolution strategies).

${ }^{15}$ See KenNeth J. ARROW, Social Choice and Individual Values $2-8$ (2d ed. 1963). 
these phenomena? Put differently, what is it about commensurability that worries theorists?

\section{A. Commodification and the Imperialism of the Market}

If I were to pick one candidate as the one most likely to lie behind the rush to embrace incommensurability, it would have to be the fear of universal commodification, assigning a market price to everything and thus making everything comparable in terms of money. ${ }^{14}$ If we barter our kidneys for food, our babies for medical procedures, our environment for creature comforts-and hence everything for money, the efficient medium of exchange-then, according to many social critics, we have become morally degraded. We have failed to see that the values at stake cannot be assigned a price and thereby made commensurable with other values. They are values beyond price because-so the argument goes-they are incommensurable values.

Now, I think this is a misdiagnosis, plain and simple. The fact is-and I commend to you a recent book review by Linda Radzik and David Schmidtz on this point ${ }^{15}$ - we do commensurate these values. That is how we are able to trade them in the market.

The problem is that we often commensurate these values incorrectly. Perhaps the surrogate mother should not trade the use of her reproductive capacities for money or the things money will buy her. Or perhaps she should not trade them for a new car, though she might be right to do so for an operation for one of her own children. If there is no price at which she should sell-even to save one of her children's lives-then the value of not renting one's womb always trumps other values. If there is a price, then the value of not renting one's womb trumps some values and is trumped by others. In either case, the values at stake are commensurable, though like all values, of course, they can be misappraised. ${ }^{16}$

14 See, e.g., MARGaret JANE RADIN, CONTESTEd COMMOdITIES 2-3 (1996) (stating that her book will take issue with economic theorists who "reflect a methodological archetype that I will call universal commodification" and noting that "[c]ommensurability is central to commodification").

${ }^{15}$ See Linda Radzik and David Schmidtz, Contested Commodities, 16 LAw \& PHIL. 603 (1997) (reviewing RADIN, supra note 14).

${ }^{16}$ Of course, believing that certain values are beyond all price, even when they are not, may lead people to trade off those values at closer to the appropriate price than they would without such a false belief. Alternatively, our erroneous belief in the incommensurability of values may lead people to give up too quickly in attempting to 
Thus, although we would act wrongly if we preferred one child over another, or if we deliberately maimed our children, it is less clear that Sophie in William Styron's Sophie's Choice acted wrongly in choosing to save her son rather than her daughter, or that the desperately poor of India act wrongly in having their children maimed to increase their begging income. Some things are beyond price in some circumstances-that is, when no superior values are threatened-but not in others. ${ }^{18}$

\section{B. Endogeneity of Preferences}

Cass Sunstein frequently has pointed out that many of our preferences are endogeneous to the particular set of laws, cultural norms, and distribution of wealth we currently have. ${ }^{19}$ If those were to change, so too would many of our preferences. Therefore, one cannot justify the present regime by reference to our preferences, because those preferences are endogeneous to the regime.

This argument suggests that preference-based justifications are incommensurable because preferences for social change are relative to both starting and ending points. I take this point, however, as closely related to the point I made about changes of values and personal continuity. The fact that we might value a change, were it to occur, that we do not value from the standpoint of who we are here and now is not an argument that can carry much force with us. The fact that our values are wrong is one thing. The fact that "we" would not hold these values under other circumstances is quite another. Our present values and the values "we" would endorse under changed

figure out how values should be compared. See Frederick Schauer, Instrumental Commensurability, 146 U. PA. L. REV. 1215 (1998).

Just as the belief in the incommensurability of values may in some circumstances result in better commensuration, so too may the rhetoric of incommensurability serve socially useful ends, even if values are in fact commensurable. See Eric A. Posner, The Strategic Basis of Principled Behavior: A Critique of the Incommensurability Thesis, 146 U. PA. L. REV. 1185, 1200-02 (1998).

${ }^{17}$ William STyRON, SOPHIE's CHOICE 483-84 (1979).

${ }^{18}$ Value incommensurability often is cited as a reason for government agencies not to employ cost-benefit analysis. I agree with Matthew Adler and Richard Craswell, however, when they raise substantial doubts about whether value incommensurability does, in fact, undermine cost-benefit analysis. See Matthew Adler, Incommensurability and Cost-Benefit Analysis, 146 U. PA. L. REV. 1371, 1417-18 (1998); Richard Craswell, Incommensurability, Welfare Economics, and the Law, 146 U. PA. L. REV. 1419, 1429-32 (1998).

${ }^{19}$ See, e.g., Cass R. Sunstein, Preferences and Politics, 20 PHIL. \& PUB. AFF. 3 (1991). 
conditions may very well be incommensurable for us, but only because we cannot imagine "ourselves" holding the latter values.

\section{Community Death}

There is an analogue at the community level to personal death on the individual level. A value might appear incommensurable with values our community presently endorses because we cannot see community identity being preserved if the former value becomes accepted. For example, if human gladiatorial contests of the sort vividly described by Irving Kristol ${ }^{20}$ were permitted in the United States, many would believe the basic identity of the community would have radically changed; we would not be the same community we were. In that sense, values are incommensurable for particular communities in the same way they are for particular persons: Some values are unavailable because they cannot be adopted without a change in identity.

\section{Totalitarianism}

Isaiah Berlin might be the progenitor of the incommensurability discussion. He asserted the plurality and irreducibility of values. ${ }^{21}$ Liberty and equality were different values. One could not be reduced to the other, nor could both be reduced to some other value.

Berlin was worried about totalitarianism, particularly the totalitarian tendencies of arguments that would cast liberty in terms of equality. That was, and is, a real worry. Nevertheless, if Berlin is correct, then a choice of liberty over equality-or the converse-cannot be justified. Because for a choice to be justifiable, the options must be comparable, which means commensurable along some dimension. The irreducibility of plural values ultimately may be a greater source of worry than their reducibility, for the former deprives us of a criticism of zealotry.

There are a lot of things that are not, but may be mistaken for, value incommensurability. And there are a lot of worries that, even if well-founded, should not lead us to assert, or to wish for, value incommensurability. The belief that values are incommensurable allows us to give up too easily on justifying our choices.

${ }^{20}$ See Irving Kristol, Pornography, Obscenity and the Case for Censorship, N.Y. TIMES, Mar. 28, 1971, § 6 (Magazine), at 24.

21 ISAIAH BERLIN, FOUR ESSAYS ON LIBERTY 167-72 (1969). 
$* * * * * * *$ 